Original Article (short paper)

\title{
Football training session rises creatine kinase but does not impair performance
}

\author{
Donizete Cicero Xavier Oliveira ${ }^{1,2} \mathbb{D}$, Ariobaldo Frisselli ${ }^{1} \mathbb{D}$, Rafael Deminice $^{1} \oplus$ \\ ${ }^{1}$ Universidade Estadual de Londrina, Centro de Educação Física e Esporte, Londrina, PR, Brasil; \\ ${ }^{2}$ Centro Universitário Filadélfia, Londrina, PR, Brasil
}

\begin{abstract}
Aim: Determine the relationship between changes in oxidative stress markers, muscle damage, DOMS, and their relationship with performance in response to a session of football training during a 1-week recovery period of young football players. Methods: Nineteen young football players aged $16.7 \pm 1.0$ years were included in the study. After initial evaluation for basal levels of oxidative stress and muscle damage markers, DOMS, and performance testing (Vertical Jump, Agility T-test, and RAST potency test), the athletes were submitted to a routine training session composed of squatting exercises, followed by a simulated football match of 45 minutes. Athletes were reevaluated for 3 consecutive days (24h, $48 \mathrm{~h}$, and $72 \mathrm{~h}$ after the training session) during the recovery week. Results: An elevated DOMS score in the quadriceps and posterior thigh $(P<0.05)$ and serum CK was observed $24 \mathrm{~h}$ to $72 \mathrm{~h}$ after the training session. Despite elevated DOMS and CK muscle damage markers, no changes were observed in the vertical jump test, RAST potency test, or agility T-test during the recovery week. In addition, no changes in the oxidative stress markers analyzed MDA, AOPP, and GSH were observed during the recovery week. Conclusion: Training sessions with squatting exercises and simulated matches promote a rise in CK and DOMS, but not sufficient to impair physical performance during the training week in young players.
\end{abstract}

Keywords: soccer, oxidative stress, muscle damage, athletic performance.

\section{Introduction}

A football match may subject the athletes to high-intensity moments, where sprints, jumps, acceleration, deceleration, and rapid changes of direction occur repeatedly; actions related to muscle damage promotion ${ }^{1}$. Indeed, these actions during a competitive football match promote fatigue and physiological stress in muscle tissue, excessive muscle damage, and delayed-onset muscular soreness (DOMS) in the days after the match ${ }^{1}$. Elevated muscle damage and DOMS are generally associated with reduced physical performance in the days of recovery $^{2}$, decreasing athletes competition appearances, and, in critical cases, leading to muscle and joint injures ${ }^{3,4}$. However, little is known about the fatigue and damage-potential of a training session of football.

Football players, especially young athletes, may play 2 to 3 matches a week during the competition season. Moreover, 2 to 3 days between matches could be insufficient for total recovery ${ }^{5}$, especially as one or two training sessions are frequently performed during the 2 to 3 days of recuperation. Training sessions between matches include individual stretching and strength exercises as well as field technical and tactical development exercises ${ }^{6}$. According to Bangsbo, Mohr, and Krustrup ${ }^{7}$, a professional player's training week is composed of 10 training sessions on average with 80 minutes of duration and an intensity of $75 \%$ of maximal heart rate, with several peaks of intensity.

Recently, several blood markers have been studied such as fatigue, muscle damage, or recuperation state indicators to help coaches and physiologists to monitor the evolution, overreaching, and overtraining state of athletes ${ }^{8}$. Among the markers used, creatine kinase (CK) and lactate dehydrogenase (LDH) have been largely used in football practices as markers of muscle damage ${ }^{9,10}$. In addition, oxidative stress and redox imbalance, first studied in disease appearance and progression, have now been demonstrated to be associated with physiological stress promoted by exercise training and sports competition ${ }^{11,12}$.

Thus, studies have demonstrated elevated plasma markers of muscle damage, DOMS, oxidative stress, and impaired performance after a football match ${ }^{1,8}$. However, little is known about the association of muscle damage markers and performance as a result of the intensity of the training session during recovery. Thus, the present study aimed to determine the relationship between changes in oxidative stress markers, muscle damage, and DOMS in response to a session of football training; and their association with possible changes during a 1-week performance recovery period in young players.

\section{Methods}

\section{Experimental approach}

All athletes were invited to attend the Laboratory of Exercise Biochemistry of the State University of Londrina and, after signing a free and informed consent, were evaluated according to body composition and anthropometry. The athletes have then 
submitted to blood collection and physical tests on 4 consecutive days. On the first day (Pre), the basal levels of blood markers and performance tests were determined after a $72 \mathrm{~h}$ rest. The participants were enrolled to a routine training, each session consisted of 150 minutes duration, the session started at 2 pm, with an ambient temperature of $23,5^{\circ} \mathrm{C}$ and relative air humidity of $66 \%$. This session consisted of the performance tests, 3 sets of 30 squats with jumps and 25 meters of a squat with the jump, followed in the sequence being a simulated soccer game of 45 minutes. The simulated match contained arbitration and organization by the team's coaches. Subsequently, blood collection and performance tests were performed $24 \mathrm{~h}, 48 \mathrm{~h}$, and $72 \mathrm{~h}$ after the training session (Figure 1). All tests and collections were performed by the same researchers, with the same periods of the day, rest time, and feeding conditions throughout the experiment.

The study was initiated only after approval by the research ethics committee of the State University of Londrina (document number: 32331314.2 .0000 .5231 ) and complied with the Helsinki Declaration.

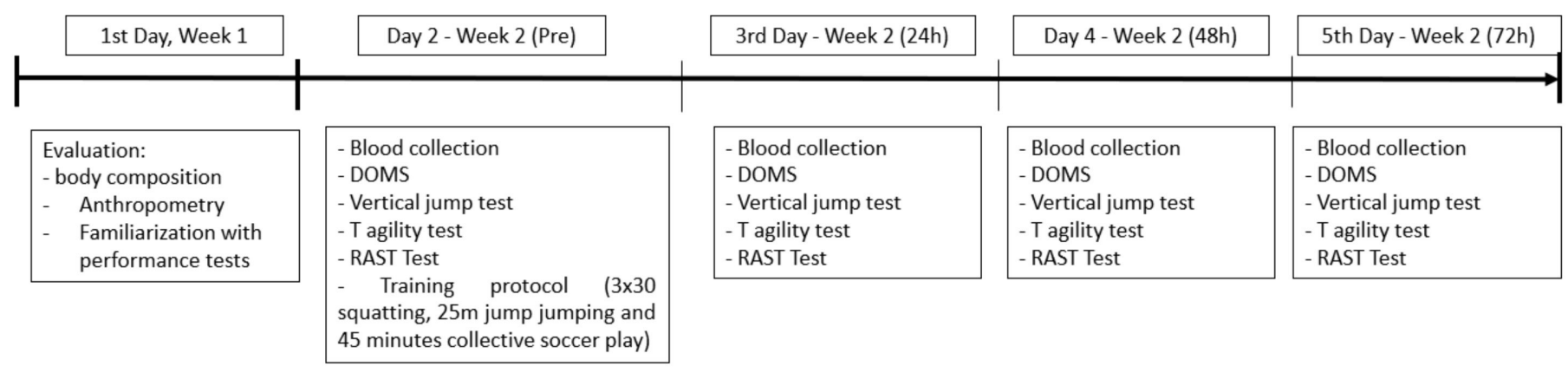

Figure 1. Experimental design.

\section{Participants}

Participated in the simulated game 22 male football players from an under-19 category soccer team in the city of LondrinaPR, Brazil. The goalkeepers were excluded from the analyses. Also, one of the players was injured and did not complete all phases of the research. Thus, a total of 19 players were included in this study ( 4 defenders, 4 siders, 7 mild-fielders, and 4 strikers). The team was in the early stages of the competition season. The athletes presented the following characteristics: $16.7 \pm 1.0$ years, $70.5 \pm 7.9(\mathrm{~kg})$ body mass, $179.0 \pm 7.7(\mathrm{~cm})$ height, and $11.7 \pm 1.8 \%$ fat mass. For the evaluation of the maturational level, the Tanner scale ${ }^{13}$ was used, by which it was observed that all the athletes were already at the stage considered mature. The team competed for the state championship of Parana, Brazil in the under-19 category. Athletes had a training routine based on 2 hours of training daily, 5 to 6 days in the week. The athletes were familiarized with all tests in the weeks before the study, which presented intra-class correction coefficient (95\%) above 0.9 and a coefficient of variation of less than $5 \%$ between sessions for all tests. Subjects were nonsmokers and had not taken any type of medication or food supplementation for a minimum period of 2 months prior to the start of the study.

\section{Anthropometric measurements}

Body mass and height were evaluated by a scale coupled to a stadiometer (Filizola ${ }^{\circledR}$, São Paulo, Brazil). Body composition evaluation was performed by the skinfold method, measured using a Lange ${ }^{\circledR}$ scientific adipometer, according to standardizations established by Lohman, Roche and Martorell ${ }^{14}$ and the 7-fold equation of Jackson and Pollock ${ }^{15}$, followed by the Siri equation, were used to estimate the percentage of body fat.

\section{Performance tests}

The battery of performance tests was performed at the pretest (before the training protocol) and $24 \mathrm{~h}, 48 \mathrm{~h}$, and $72 \mathrm{~h}$ after the football training session. Performance tests consisted of recognized football applied tests such as the Counter Movement jump test (CMJ), agility T-test, and running-based anaerobic sprint test (RAST), performed in this sequence on the evaluation days, as shown in figure 1. The CMJ was performed using a Smartspeed ${ }^{\circ}$ (Fusion Sport, Australia) jump platform, considering the highest value of three attempts, with 2 a minute interval between each jump. The T agility test was performed as described by Guincho ${ }^{16}$, where 4 cones were placed in a T-shape with a 5 meter distance between each, forming a circuit in which the athlete was required to run in the shortest time possible. The better of the two attempts was recorded. The RAST test ${ }^{17}$ was performed as described by Zagatto, Beck, and Gobatto ${ }^{18}$, with 6 sprints of 35 meters at maximum speed with a 10 -second interval between each sprint. Both the agility T-test and RAST were evaluated using Hidrofit ${ }^{\circledR}$ (Brazil) photocells. A 5-minute interval was provided between all tests. The tests followed the same sequence every day, as well as the order of the players, which was previously randomized. 


\section{Blood collections and biochemical analyzes}

Blood collections were performed by puncture of the antecubital vein and samples were collected in $6 \mathrm{ml}$ vacuum tubes containing heparin. The tubes were centrifuged at $1,000 \mathrm{~g}$ for 15 minutes. The plasma was stored in Eppendorf tubes at $-80^{\circ} \mathrm{C}$ and the analysis was completed no later than two months after collections.

Plasma CK and LDH enzyme activity, used as markers of muscle damage, were measured using commercial kits from Labtest ${ }^{\mathbb{B}}$ (Lagoa Santa, Minas Gerais, Brazil). Circulation advanced oxidation protein products (AOPP) and malondialdehyde (MDA), markers of oxidative damage, were measured according to proposals by Witko-Sarsat, Friedlander, Capeillère-Blandin, Nguyen-Khoa, Nguyen, Zingraff $^{19}$ and Spirlandeli, Deminice, and Jordão ${ }^{20}$, respectively. Reduced glutathione (GSH) plasma concentration was determined as described by Rahman, Kode and Biswas ${ }^{21}$, and used to determine imbalanced redox state. All biochemical analyses were performed through plate reading in an Epoch microplate spectrophotometer (Bioteck $^{\circledR}$, Vermont, USA). The intrassay coefficients of variation were less them $5 \%$ for all analysis.

\section{DOMS evaluation}

For the evaluation of DOMS, a 10-point visual analogue scale was used, marked from "no pain" (0) to "worst possible pain" (10). Athletes were asked to mark their level of pain on the DOMS scale by maintaining a half squatting position, as described by Miyama and Nosaka ${ }^{22}$, with a pressure exerted by the evaluator's index and middle fingers on the evaluated muscles; femoral quadriceps, calf, abdomen, and posterior thigh. The athletes were previously familiarized with the DOMS scale.

\section{Statistical analysis}

Data are presented as mean and standard deviation. For the data normality analysis, the Shapiro-Wilk test and the Mauchly sphericity test was used. When necessary the Greenhouse-Geisser correction was used. The data were compared using the ANOVA one-way tests for repeated measures. The Sidak test (post hoc) for a level of significance for multiple comparisons was used when necessary to identify differences between sampling times during the recovery week. In all cases, values of $\mathrm{P}<0.05$ were considered significant. The SPSS 22.0 statistical package was used for all data analysis.

\section{Results}

Table 1 presents the data of DOMS determined pre and 24, 48 , and $72 \mathrm{~h}$ after the training session. The data demonstrated a significant increase in DOMS in the quadriceps femoral muscle $(\mathrm{P}<0,001 ; \mathrm{F}=27,5)$, posterior thigh muscles $(\mathrm{P}<0,001 ; \mathrm{F}=24,19)$, and the sum of muscle groups studied $(\mathrm{P}<0,001 ; \mathrm{F}=35,18)$. No significant changes were found in DOMS calf $(\mathrm{P}=0,20 ; \mathrm{F}=1,6)$ and abdomen muscle $(\mathrm{P}=0,16 ; \mathrm{F}=1,8)$ scores.

Table 1. DOMS determined pre and 24,48 and $72 \mathrm{~h}$ after the training session.

\begin{tabular}{lclll}
\hline Muscle groups & Pre & \multicolumn{1}{c}{$\mathbf{2 4 h}$} & $\mathbf{4 8 h}$ & $\mathbf{7 2 h}$ \\
\hline Quadriceps & $0.1 \pm 0.3$ & $0.7 \pm 0.8^{*}$ & $2.7 \pm 1.5^{* \#}$ & $1.5 \pm 1.2^{*}$ \\
Calf & $0.1 \pm 0.3$ & $0.1 \pm 0.3$ & $0.1 \pm 0.2$ & $0.2 \pm 0.5$ \\
Posterior thigh & $0.1 \pm 0.3$ & $0.6 \pm 0.7$ & $2.5 \pm 1.4^{* \#}$ & $1.3 \pm 1.2^{*}$ \\
Abdomen & $0.0 \pm 0.2$ & $0.2 \pm 0.5$ & $0.2 \pm 0.7$ & $0.4 \pm 0.6$ \\
$\sum$ & $0.3 \pm 0.6$ & $1.6 \pm 1.1^{*}$ & $5.4 \pm 2.3^{* \#}$ & $3.4 \pm 2.7^{*}$ \\
\hline
\end{tabular}

Values expressed in arbitrary units (AU) in mean \pm Standard Deviation. * Significant difference of the moment Pre. \# Significant difference for $24 \mathrm{~h}(\mathrm{P}<0,01)$. $\sum$ Sum of DOMS in muscle groups.

Table 2 shows the markers of muscle damage and oxidative stress determined before and 24, 48, and 72 hours after the training session with a simulated match. The training session proposed was able to promote a significant increase $(\mathrm{P}<0.01$; $\mathrm{F}=13,86$ ) in the plasma concentration of $\mathrm{CK}$, which remained elevated for up to $72 \mathrm{~h}$. However, the same was not demonstrated for the circulating concentration of $\operatorname{LDH}(0=0,25 ; \mathrm{F}=1,4)$ or any markers of oxidative stress measured (MDA, $\mathrm{P}=0,23 ; \mathrm{F}=1,5$; AOPP, $\mathrm{P}=0,06 ; \mathrm{F}=2,7$; $\mathrm{GSH}, \mathrm{P}=0,38 ; \mathrm{F}=1,02$ ).

Table 2. Markers of muscle damage and oxidative stress determined pre, 24, 48 and $72 \mathrm{~h}$ after the training session.

\begin{tabular}{lcccc}
\hline \multicolumn{1}{c}{ Groups } & Pre & $\mathbf{2 4 h}$ & $\mathbf{4 8 h}$ & $\mathbf{7 2 h}$ \\
\hline Muscle Damage & & & $381.0 \pm 171.0^{*}$ & $427.0 \pm 207.0^{*}$ \\
CK $(\mathrm{U} / \mathrm{L})$ & $147.3 \pm 60.0$ & $404.0 \pm 214.0^{*}$ & $149.2 \pm 46.0$ & $137.8 \pm 33.0$ \\
LDH $(\mathrm{U} / \mathrm{L})$ & $138.7 \pm 28.0$ & $155.8 \pm 33.0$ & & \\
Oxidative stress & & & $8.9 \pm 2.0$ & $9.5 \pm 0.0$ \\
MDA $(\mu \mathrm{mol} / \mathrm{g} \mathrm{pt})$ & $10.1 \pm 3.2$ & $9.3 \pm 1$ & $1098.0 \pm 217.0$ & $1272 \pm 237.0$ \\
AOPP $(\mu \mathrm{mol} / \mathrm{g} \mathrm{pt})$ & $1150.0 \pm 194.0$ & $1095.0 \pm 270.0$ & $756.0 \pm 204.0$ & $779.0 \pm 169.0$ \\
GSH $(\mu \mathrm{mol} / \mathrm{L})$ & $835.0 \pm 292.0$ & $757.0 \pm 204.0$ & \\
\hline
\end{tabular}

Values expressed \pm mean and Standard Deviation. $\mathrm{g} \mathrm{pt}=$ grams of protein.

* Significant difference to the moment Pre $(\mathrm{P}<0.01)$. 
Figure 2 presents the results of the 3 performance tests performed at pre and $24 \mathrm{~h}, 48 \mathrm{~h}$, and $72 \mathrm{~h}$ after the training session. No significant differences were demonstrated for the relative power of the lower limbs analyzed by the vertical jump test $(\mathrm{P}=0,28 ; \mathrm{F}=1,30)$ (Figure $2 \mathrm{a})$. The athletes had a shorter execution time in the T-agility test at $48 \mathrm{~h}$ and $72 \mathrm{~h}$ compared with pre and $24 \mathrm{~h}(\mathrm{P}<0,001 ; \mathrm{F}=33,52)$ (Figure 2b). RAST test demonstrated no significant difference in the fatigue

a)

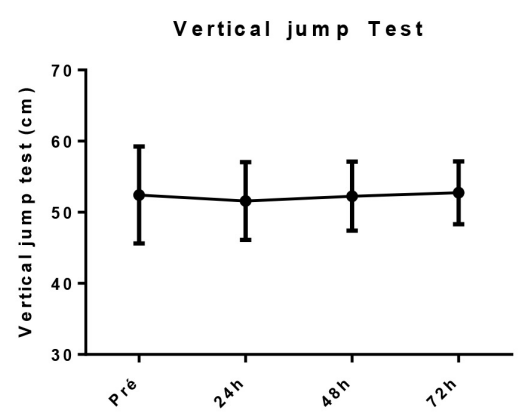

d)

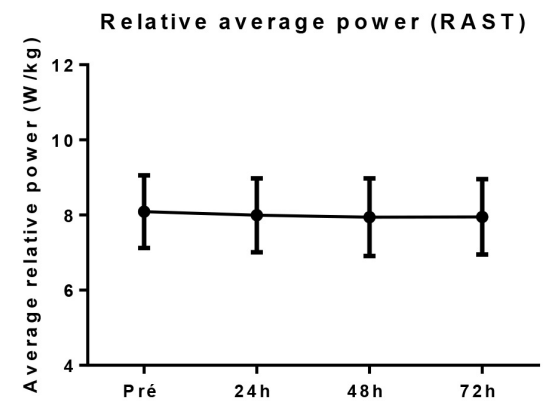

b)

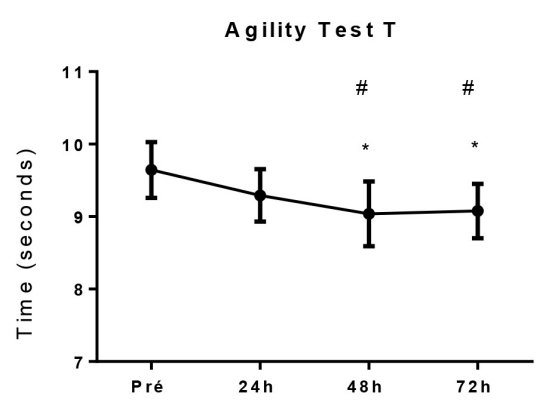

e)

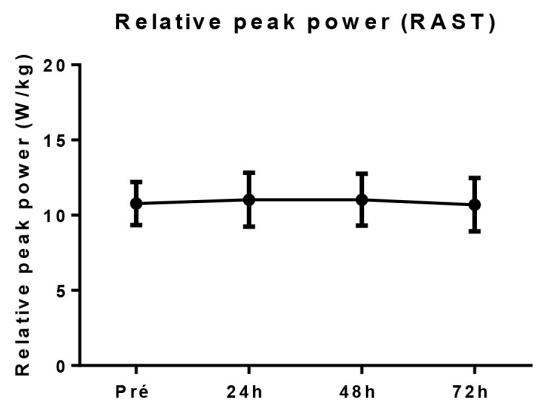

c)

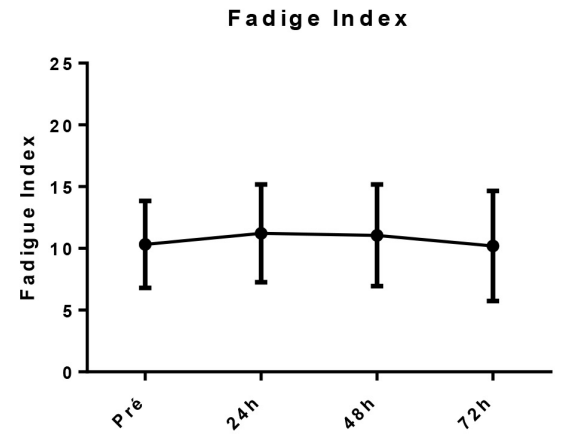

f)

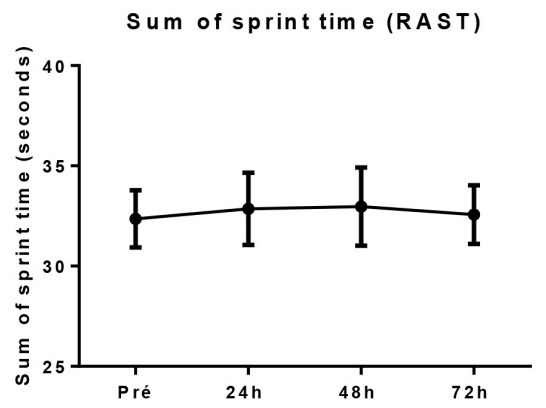

Figure 2. Vertical jump height (a) Agility test T (b), in RAST test fatigue index (c), relative average power (d), relative peak power (e) and sum of sprint time (f). The data are presented in mean $\pm \mathrm{SD}$. $\mathrm{N}=19$. * Difference from pre, \# difference from $24 \mathrm{~h}$. $\mathrm{P}<0.05$.

\section{Discussion}

The main results of this study were: (A) the elevation of circulating CK concentration was related with the appearance of DOMS after a training session with a simulated football match; (B) the elevation of CK and DOMS at the observed levels did not reduce agility, jump, or running power performance; (C) no differences were observed in the plasma concentration of oxidative stress markers after the training session.

In the present study, the proposed training session, composed of squats exercises followed a simulated football match can promote $\mathrm{CK}$ and DOMS elevation. It is known that a competitive football match is able to elevate CK and DOMS up to $48 \mathrm{~h}$ after the match ${ }^{1,8,23}$. To the best of our knowledge, this is the first study to demonstrate that a routine training session can promote significant changes in skeletal muscle markers of damage in football players.
Serum CK levels are classically used as a tool in the diagnosis of myocardial infarction as raised levels are closely associated with cell damage and muscle cell disruption ${ }^{24}$. Since it is related to heart muscle damage, CK has been extensively studied as a skeletal muscle damage marker following physical exercise. Studies have demonstrated intensive exercise causes a greater disruption or injury to the muscle tissues which may cause CK to leak from cells into blood serum ${ }^{25,26}$. Although several studies have demonstrated great increases in serum CK after different exercise modalities, there is still a significant discussion in the literature about the use of CK blood levels as a single tool to identify muscle damage. As an alternative, other additional indirect indices of muscle damage such as DOMS have been utilized in many studies ${ }^{24}$. DOMS reflects the sensation of discomfort or pain in specific muscular groups following exercise, which can be measured using a visual scale. Thus, the elevated CK and DOMS demonstrated 
in the present study after the proposed set of plyometric and eccentric exercises indicate that it was enough to promote muscle damage.

However, despite elevated CK and DOMS, athletes did not demonstrate decreased physical performance during the recovery week determined by specialized football tests. This seems controversial since pain and discomfort induced by muscle tissue disruption can cause reduced muscle force, swelling, and reduced range of movement ${ }^{27}$. However, the magnitude of elevated CK and DOMS demonstrated in our study appears to be small, or not intense enough to cause impaired performance. Ascensão, Rebelo, Oliveira, Marques, Pereira, Magalhães ${ }^{8}$ demonstrated a reduction in the strength of the lower limbs for up to 72 hours after a competitive football match, evaluated by isokinetic force and 20-meter sprints. This small reduction in performance was accompanied by an increase in the concentration of CK and DOMS (CK and DOMS elevation peak of $\sim 800 \mathrm{UL}^{-1}$ and 4.0 , respectively at $24 \mathrm{~h}$ after the match). Ispirlidis et $\mathrm{al}^{28}$ also demonstrated reduced sprint and vertical jump performance associated with elevated $\mathrm{CK}$ and DOMS (CK and DOMS elevation peak of $\sim 800 \mathrm{U} / \mathrm{L}$ at $48 \mathrm{~h}$ and 8 at $24 \mathrm{~h}$ respectively at $24 \mathrm{~h}$ after the match) up to $72 \mathrm{~h}$ after a competitive football match. Silva, Ascensão, Marques, Seabra, Rebelo, Magalhães ${ }^{29}$ demonstrated elevated CK ( 900 U/L) $24 \mathrm{~h}$ after a football match that was coincident with reduced vertical jump performance. In fact, an official/competitive football match has been demonstrated to elevate CK to 800 to $900 \mathrm{U} / \mathrm{L}$ and DOMS to around scale 4 to 8 , which promotes impaired performance in subsequent days ${ }^{8,28,29}$. However, despite the statistically significant elevation $(P<0.05)$ demonstrated in the present study, the elevation in CK and DOMS found after a training session with a simulated match was half that demonstrated after a competitive match ${ }^{8,28,29}$.

Regarding LDH, although we observed an increase in the concentration in $24 \mathrm{~h}$ and $48 \mathrm{~h}$, this increase was not significant, which differs from other results found in the literature ${ }^{23,30}$. However, as presented by Bessa, et al. ${ }^{31}$, the magnitude of elevation of $\mathrm{LDH}$ is much lower in relation to $\mathrm{CK}$; Thus, the intensity of training may not promote a significant difference in a football training session, which had not yet been observed in the literature. It is important to note that the concentrations of $\mathrm{CK}$ and $\mathrm{LDH}$, in this study, had their basal values in the biological parameters of the normal range, according to the ranges available in the analysis biochemicals kits.

Indeed, the elevation of serum CK and DOMS in the absence of performance loss lead us to inquire whether raised $\mathrm{CK}$ after exercise does represent a degree of actual muscle damage or some form of alteration in cell membrane permeability, metabolic disturbance, or even another molecular reaction mechanism. Baird, Graham, Baker, Bickerstaff ${ }^{24}$ suggested that the appearance of $\mathrm{CK}$ in serum following low- to moderateintensity exercise represents a disturbance in muscle energy processes, but not muscle disruption or cell damage, as observed following myocardial infarction or other physical/structural damage. Other markers may be used together to determine the levels of injury induced by exercise related to impaired performance.
The results showed increased performance in the agility T-test, even with the increase of DOMS at 24 and $48 \mathrm{~h}$ after the training session, even though a familiarization session was completed in the week before the training session. It is suggested that this fact occurred due to the learning process of the test, as observed in earlier studies with agility test ${ }^{32,33}$. This question should still be the object of exhaustive research and discuss in the assessment of sports performance.

Reactive oxygen species (ROS) produced during exercise may also be involved in muscle damage related to inflammation and DOMS. Oxidative stress not only directly causes damage by oxidation of cell components (i.e., lipids, protein, DNA), but also acts as a regulator of inflammation ${ }^{34}$. Prolonged and high-intensity exercise leads to oxidative stress due to the increased ROS that signals for phagocytes infiltrate expressing cytokines, chemokines, and adhesion molecules, resulting in proteolysis, protein ultrastructural damage, and oxidative injury ${ }^{35}$. Indeed, oxidative stress and inflammation blood markers have been tested as additional measures to assist in quantifying and substantiating muscle disturbance parameters ${ }^{36,37}$. The present study, however, demonstrated that the oxidative stress biomarkers analyzed (MDA, AOPP, and GSH) did not change blood concentrations in response to the training session, despite the elevation of $\mathrm{CK}$ and DOMS. This highlights the integrated complexity of the mechanisms of muscle damage and the indices used to measure it. CK, oxidative stress markers, and DOMS, which are mainly a result of micro-damage within the myocytes, may not necessarily lead to performance loss consequences. The age of the athletes was not an intervening factor in the analysis, considering that all the athletes, although young, were at a mature stage.

The present study has one limitation that should be considered. We used a training session proposed as routine by the coaches; however, the intensity of the effort was not quantified during the training session, which does not enable us to directly compare our results with others using intensity or perception of effort scales.

As a practical application, the elevated CK blood concentration was associated with an increased DOMS score after a training football session; the same was not demonstrated for the oxidative stress markers tested. In addition, despite elevated DOMS and CK muscle damage markers, athletes did not experience a reduction in specific performance tests during the training week. These results suggest that only DOMS and CK are not sufficient to evaluate and / or predict performance. Thus, questionnaires and thermography analyses might be necessary for a better diagnosis for the evaluation of young soccer players in recovery periods.

\section{Conclusions}

In conclusion, training sessions with squatting exercises, and simulated matches promote a rise in CK and DOMS, but not sufficient to impair physical performance during the training week in young players. 


\section{References}

1. Mohr M, Draganidis D, Chatzinikolaou A, Barbero-Álvarez JC, Castagna $\mathrm{C}^{6}$, Douroudos I, et al. Muscle damage, inflammatory, immune and performance responses to three football games in 1 week in competitive male players. Eur J Appl Physiol. 2016; 116: 179-193.

2. Nédelec M, McCall A, Carling C, Legall F, Berthoin S, Dupont G. Recovery in soccer: Part II-recovery strategies. Sport Med. 2013; 43: 9-22.

3. Ekstrand J, Walde M, Hagglund M. A congested football calendar and the wellbeing of players: correlation between match exposure of European footballers before the World Cup 2002 and their injuries and performances during that World Cup. Br J Sports Med. 2004; 38: 493-497.

4. Dupont G, Nedelec M, McCall A, McCormack D, Berthoin S, Wisløff U. Effect of 2 Soccer Matches in a Week on Physical Performance and Injury Rate. Am J Sports Med. 2010; 38: 1752-1758.

5. Ascensão A, Rebelo A, Oliveira E, Marques F, Pereira L, Magalhães J. Biochemical impact of a soccer match - analysis of oxidative stress and muscle damage markers throughout recovery. Clin Biochem. 2008; 41: 841-851.

6. Scott BR, Lockie RG, Knight TJ, Clark AC, Janse de Jonge XAK. A Comparison of Methods to Quantify the In-Season Training Load of Professional Soccer Players. Int J Sport Physiol Perform. 2012; 5: 5 .

7. Bangsbo J, Mohr M, Krustrup P. Physical and metabolic demands of training and match-play in the elite football player. J Sports Sci. 2006; 24: 665-674.

8. Ascensão A, Rebelo A, Oliveira E, Marques F, Pereira L, Magalhães J. Biochemical impact of a soccer match - analysis of oxidative stress and muscle damage markers throughout recovery. Clin Biochem. 2008; 41: 841-851.

9. Rowlands DS, Pearce E, Aboud A, Gillen JB, Gibala MJ, Donato S. Oxidative stress, inflammation, and muscle soreness in an 894-km relay trail run. Eur J Appl Physiol. 2012; 112: 1839-1848.

10. Cruzat VF, Rogero MM, Borges MC, TirapeguiJ. Aspectos atuais sobre estresse oxidativo, exercícios físicos e suplementação. Rev Bras Med do Esporte. 2007; 13: 336-342.

11. Powers SK, Radak Z, Ji LL. Exercise-induced oxidative stress: past, present and future. J Physiol. 2016; 594: 5081-5092.

12. Byrne C, Twist C, Eston R. Neuromuscular Function After ExerciseInduced Muscle Damage Theoretical and Applied Implications. Sport Med. 2004; 34: 49-69.

13. Tanner J. Growth at adolescence. Oxford: Blackwell, 1962.

14. Lohman TG, Roche AF, Martorell R. Anthropometric standardization reference manual. Hum Kinet Books. 1988; 177.

15. Jackson AS, Pollock ML. Generalized equations for predicting body density of men. Br J Nutr. 1978; 40: 497-504.

16. Guincho AD de C. Relação entre três testes de agilidade: Teste T, Teste 505 e Teste ZIG-ZAG: influência do estatuto maturacional, idade cronológica e idade de treino na performance dos três testes.". Faculdade do Porto, 2007.

17. Zacharogiannis E, Paradisis G, Tziortzis S. An evaluation of tests of anaerobic power and capacity an evaluation of tests of anaerobic power and capacity. Med Sci Sports Exerc. 2004; 36: S116.
18. Zagatto AM, Beck WR, Gobatto CA. Validity of the running anaerobic sprint test for assessing anaerobic power and predicting short-distance performances. J Strength Cond Res. 2009; 23: $1820-1827$.

19. Witko-Sarsat V, Friedlander M, Capeillère-Blandin C, Nguyen-Khoa T, Nguyen AT, Zingraff J. Advanced oxidation protein products as a novel marker of oxidative stress in uremia. Kidney Int. 1996; 49: 1304-1313.

20. Spirlandeli AL, Deminice R, Jordao AA. Plasma malondialdehyde as biomarker of lipid peroxidation: Effects of acute exercise. Int J Sports Med. 2014; 35: 14-18.

21. Rahman I, Kode A, Biswas S. Assay for quantitative determination of glutathione and glutathione disulfide levels using enzymatic recycling method. Nat Protoc. 2006; 1: 3159-65.

22. Miyama M, Nosaka K. Influence of surface on muscle damage and soreness induced by consecutive drop jumps. J Strength Cond Res. 2004; 18: 206-211.

23. Trajkovic N, Sporis G, Vlahovic T, Madic D, Gusic M. PostMatch Changes in Muscle Damage Markers among U-21 Soccer Players. J Sport Sci Med. 2018; 7: 49-53.

24. Baird MF, Graham SM, Baker JS, Bickerstaff GF. Creatinekinase- and exercise-related muscle damage implications for muscle performance and recovery. J Nutr Metab. 2012; 2012: $1-13$.

25. Clarkson PM, Hubal MJ. Exercise-induced muscle damage in humans. Am J Phys Med Rehabil. 2002; 81: S52-S69.

26. Romagnoli M, Sanchis-Gomar F, Alis R, Risso-Ballester J, Bosio A, Graziani RL. Changes in muscle damage, inflammation, and fatigue-related parameters in young elite soccer players after a match. J Sports Med Phys Fitness. 2016; 56: 1198-1205.

27. Lee J, Goldfarb AH, Rescino MH, Hegde S, Patrick S, Apperson K. Eccentric exercise effect on blood oxidative-stress markers and delayed onset of muscle soreness. Med Sci Sports Exerc. 2002; 34: 443-448.

28. Ispirlidis I, Fatouros IG, Jamurtas AZ, Nikolaidis MG, Michailidis I, Douroudos I, et al. Time-course of changes in inflammatory and performance responses following a soccer game. Clin J Sport Med. 2008; 18: 423-431.

29. Silva JR, Ascensão A, Marques F, Seabra A, Rebelo A, Magalhães J. Neuromuscular function hotmonal and redox status and muscle damage of professional soccer players after a high-level competitive match. Eur J Appl Physiol. 2013; 113: 2193-2201.

30. Souglis A, Bogdanis GC, Chryssanthopoulos C, Apostolidis N, Geladas ND. Time Course of Oxidative Stress, Inflammation, and Muscle Damage Markers for 5 Days After a Soccer Match: Effects of Sex and Playing Position. J strength Cond Res. 2018; 32: 2045-2054.

31. Bessa AL, Oliveira VN, Agostini GG, Oliveira RJ, Oliveira AC, White GE, et al. Exercise Intensity and Recovery: Biomarkers of Injury, Inflammation, and Oxidative Stress. J strength Cond Res. 2016; 30: 311-9.

32. Beekhuizen KS, Davis MD, Kolber MJ, Cheng MS. Test-retest reliability and minimal detectable change of the hexagon agility test. J Strength Cond Res. 2009; 23: 2167-2171.

33. Stewart PF, Turner AN, Miller SC. Reliability, factorial validity, and interrelationships of five commonly used change of direction speed tests. Scand J Med Sci Sports. 2014; 24: 500-506. 
34. Aoi W, Naito Y, Takanami Y, Kawai Y, Sakuma K, Ichikawa H, et al. Oxidative stress and delayed-onset muscle damage after exercise. Free Radic Biol Med. 2004; 37: 480-487.

35. Kozakowska M, Pietraszek-Gremplewicz K, Jozkowicz A, Dulak J. The role of oxidative stress in skeletal muscle injury and regeneration: focus on antioxidant enzymes. J Muscle Res Cell Motil. 2015; 36: 377-393.

36. Takam RDM, Ama Moor VJ, Nansseu JRN, Pieme CA, Azabji MK, Tankeu F, et al. Effects of chronic strenuous physical exercise on oxidative stress and antioxidant capacity in Sub-Saharan African professional soccer players. Eur J Sport Med. 2016; 3: 15-25.

37. Le Moal E, Groussard C, Paillard T, Chaory K, Le Bris R, Plantet K, et al. Redox Status of Professional Soccer Players is Influenced by Training Load Throughout a Season. Int J Sports Med. 2016; 37: 680-686.

\section{Corresponding author}

Donizete Cicero Xavier de Oliveira

Department of Physical Education, Faculty of Physical Education and Sport, State University of Londrina. Rodovia Celso Garcia Cid | Pr 445 Km 380, Campus Universitário, Londrina, Paraná, Brazil.

Email: doni@professor.sp.gov.br

Manuscript received on March 4, 2019

Manuscript accepted on August 10, 2019

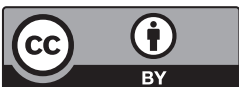

Motriz. The Journal of Physical Education. UNESP. Rio Claro, SP, Brazil - eISSN: 1980-6574 - under a license Creative Commons - Version 4.0 